\title{
Intercomparing drifts from RAFOS and profiling floats in the deep western boundary current along the Mid-Atlantic Ridge*
}

\author{
FRANCISCO MACHÍN ${ }^{1}$, UWE SEND ${ }^{2}$ and WALTER ZENK ${ }^{2}$ \\ ${ }^{1}$ Departamento de Física, Facultad de Ciencias del Mar, Universidad de Las Palmas de Gran Canaria, Campus de Tafira, \\ 35017 Las Palmas de Gran Canaria, Spain. E-mail: fmachin@becarios.ulpgc.es \\ ${ }^{2}$ Forschungsbereich: Ozeanzirkulation und Klima, Physikalische Ozeanographie II, Leibnitz-Institut für \\ Meereswissenschaften an der Universität Kiel, Germany.
}

\begin{abstract}
SUMMARY: The Lagrangian nature of cycling floats is evaluated in the framework defined by the Deep Western Boundary Current of the Mid-Atlantic Ridge. In a statistical approach, speeds and drifts are estimated for an APEX cycling float and compared with the velocities inferred from a park ensemble of four eddy-resolving RAFOS floats. They were deployed at the same location and ballasted for drifting at the same mission depth. Displacement errors induced by geostrophic shear and wind forced currents are analyzed. We observe that the velocity estimated from the RAFOS floats is not statistically different from the velocity estimated from the APEX float. Likewise, the initial separation between the cycling float and a simultaneously deployed RAFOS float has been studied in terms of the turbulent diffusivity. Though the performance of this study in comparable cases without a mean current field may be limited, these oceanic observations support exploiting the Lagrangian nature of the cycling floats.
\end{abstract}

Keywords: cycling float, APEX, RAFOS, Lagrangian, Deep Western Boundary Current (DWBC)

RESUMEN: COMPARACIÓN DE FLOTADORES RAFOS Y DERIVADORES-PERFILADORES AUTÓNOMOS APEX EN LA CORRIENTE Profunda de Frontera Oeste de la Dorsal Centroatlántica. - En este trabajo se examina la naturaleza lagrangiana de los derivadores-perfiladores autónomos en el contexto definido por la Corriente Profunda de Frontera Oeste de la Dorsal Centroatlántica. Desde un punto de vista estadístico, se comparan la velocidad y trayectoria subsuperficiales de una boya APEX con las estimadas a partir de un conjunto de cuatro boyas subsuperficiales RAFOS. Todas fueron lanzadas en la misma posición y lastradas para derivar a la misma profundidad. Asimismo, se ha analizado el error inducido por el cizallamiento vertical de la velocidad debida tanto a la geostrofía como a Ekman. En este sentido, hemos comprobado que la velocidad estimada por medio de los derivadores RAFOS no es estadísticamente diferente de la estimada por el perfilador APEX. Por otro lado, la separación inicial de las boyas se ha estudiado en términos de la difusividad turbulenta del medio. Finalmente, podemos afirmar que estas observaciones apoyan el aprovechamiento de la naturaleza lagrangiana de los derivadores-perfiladores.

Palabras clave: derivador-perfilador autónomo, APEX, RAFOS, Lagrangiana, Corrriente Profunda de Frontera Oeste.

\section{MOTIVATION}

The World Ocean Circulation Experiment (WOCE) applied various methods for observing directly the velocity fields at intermediate and

*Received November 24, 2004. Accepted June 10, 2005. abyssal depths. In this international effort an unprecedented number of subsurface floats were launched as Lagrangian current meters to map the current field at selected levels. The ultimate goal was to infer the absolute velocity of the general ocean circulation (Davis and Zenk, 2001). During WOCE two different float types were used: 
- Passive neutrally buoyant RAFOS floats and

- cycling floats capable of active control of the instruments' drift level.

The technology of eddy resolving RAFOS floats with daily subsurface fixes was already available at the beginning of WOCE (Rossby et al., 1986; Gould, 2005). Early floats (SOFAR floats) had the sound sources on them, while the receivers were moored. By reversing this (RAFOS=SOFAR spelled backwards), RAFOS only had to received the signal instead of sending it. This reduced costs because relatively few sound sources were used for larger numbers of floats. For RAFOS floats, underwater positions are calculated from sound signals emitted from moored sound sources. Having precise knowledge of the time of sound emission from the mooring and the time of arrival of this signal at the float, the distance between the two can be computed by multiplying the sound travel time with the (reasonably well-known) speed of sound. Receiving signals from several sound sources then results in a unique position fix similar to conventional radio positioning systems like DECCA or GPS. This technique uses the fact that sound can travel over basin-scale distances within the ocean, particularly at middepth (in the so-called SOFAR channel, "sound fixing and ranging"). However, soon it was recognized that some areas of the world's oceans would be simply too large to obtain the necessary insonification for roving RAFOS floats. This led to the accelerated development of cycling autonomous Lagrangian circulation explorers (ALACE) for recording the low-frequency part of the current spectrum (Davis et al., 1992). Further developments of this instrument type include profiling capabilities for temperature and salinity between the drift level (1000 $2000 \mathrm{~m}$ ) and the surface. In contrast to RAFOS floats, the cycling floats report their observational results after every dive cycle via a satellite link. Examples of cycling floats are the P/ALACE -P for profiling- (Davis et al., 1992), the more recent SOLO (Davis et al., 2001), APEX (WRC, Inc., http://www.webbresearch.com/apex.htm), and the French PROVOR floats (Loaec et al., 2002). This cycling property makes them especially suitable for operational purposes as requested by Argo, the world-wide array of profilers that provide a description of the present climatic state of the ocean and to a limited extent - forecast its future conditions (www.argo.ucsd.edu/).

The concept of Argo as a major legacy of WOCE builds on the existing upper-ocean thermal network based on XBTs (Smith et al., 2001), by extending its spatial and temporal coverage, depthrange and accuracy. After being deployed, Argo floats generally disperse over wide areas of the ocean serving as almost randomly distributed roving sources of hydrographic information of the upper ocean. In the build-up phase of the Argo network, since about 2000, analysis of its resulting data flow has mainly concentrated on the reported stratification and its accuracy (Wong et al., 2003; Böhme and Send, 2005).

The aim of this paper is to examine to what extent cycling float trajectories can be interpreted in a Lagrangian sense as an instrument which follows the water parcels perfectly, since the displacements during the surfacing intervals prevent them from being truly Lagrangian subsurface floats. We do so by carefully comparing the trajectory of a cycling float with trajectories from neutrally buoyant floats. The completely independent reference in this floatto-float intercomparison originates from a synoptic experiment with observations from one RAFOS float along the mid-ocean ridge of the North Atlantic, between Charlie Gibbs Fracture Zone (CGFZ) and the Azores archipelago.

\section{THE EXPERIMENT SITE}

Observations for this study are the result of cooperation between the Leibnitz-Institut für Meereswissenschaften and the Federal Maritime and Hydrographic Agency in Hamburg. During METEOR cruise 45, a set of four RAFOS floats and one APEX float were launched at $51^{\circ} 50^{\prime} \mathrm{N}$, $29^{\circ} 31^{\prime} \mathrm{W}$ on 19 June 1999 . The test field lies at the north-eastern rim of the subtropical gyre of the North Atlantic (Fig. 1).

The Mid-Atlantic Ridge (MAR) at $52^{\circ} \mathrm{N}$ shows a major eastward shift of about $5^{\circ}$ in longitude, the well known CGFZ. This pronounced gap in the ridge acts as a topographic control feature for the zonal exchange of water masses (Bower et al., 2002; Faure and Speer, 2005). The low-saline Labrador Sea Water (LSW), the water mass sampled by these floats at their mission depth (1500-1700 m, Table 1), is located beneath the North Atlantic Current (Krauss, 1986). In an inversion of a large data set of historical hydrographic observations Paillet, Arhan and McCartney have shown that eastward spreading LSW reaches the MAR at CGFZ where further propagation is blocked. LSW at an intermediate depth of $\sim 1500$ m bifurcates 


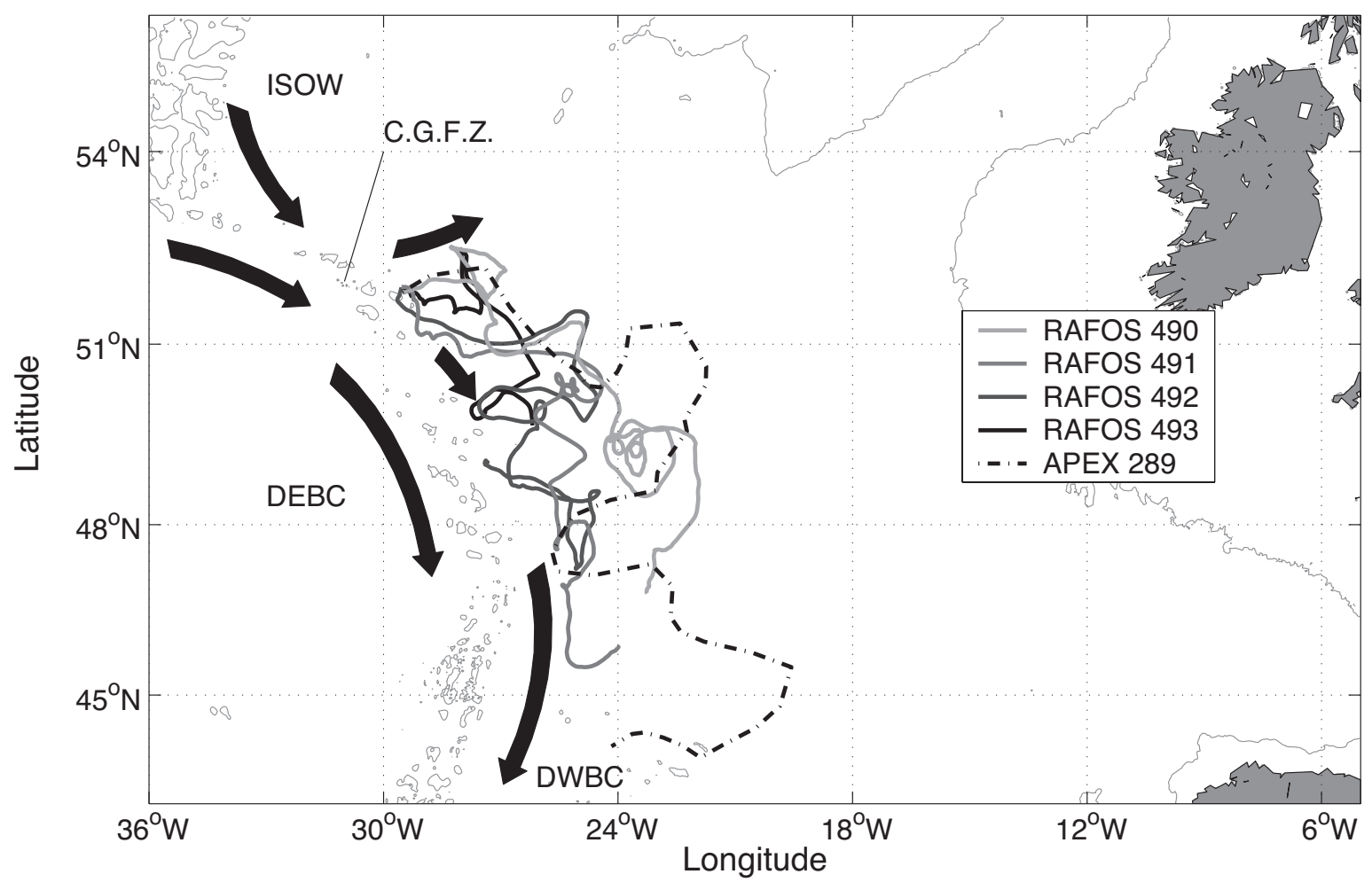

FIG. 1. - Region of study with four RAFOS and the APEX float trajectories superimposed. Black arrows indicate the currents in the region: DEBC (Deep Eastern Boundary Current), DWBC (Deep Western Boundary Current), ISOW (Iceland-Scotland Overflow Water). C.G.F.Z. stands for Charlie-Gibbs Fracture Zone.

and a fraction is diverted west of the ridge, where it forms a deep eastern boundary current (DEBC) in the western Atlantic (Fig. 1). The remaining fraction that is advected through CGFZ diverges once again: a northern branch fills the Iceland Basin with LSW and the adjacent southern branch joins Iceland-Scotland Overflow Water (ISOW) to originate the deep western boundary current (DWBC) along the eastern side of the MAR.

\section{Flow paths and hydrographic conditions}

Figure 1 displays the trajectories from all four RAFOS floats (no. 490-493), as well as from the APEX float (no. 289). The RAFOS fleet started their drift with zero, two, four, and six month delays with respect to the APEX launch, at exactly the same position (Schott et al., 2000), i.e. at the eastern end of the southern channel of the CGFZ. RAFOS floats 491-493 delayed their drift by means of a float park employed for each float (Zenk et al., 2000). Their mission lengths are included in Table 1.

The APEX float was launched simultaneously with the first RAFOS float (490) on 19/6/1999. The cycling APEX float 289 was advected by the deep boundary current in a similar way to the RAFOS floats. The large zonal excursions of the APEX path, in contrast to the reference fleet at depths, are remarkable. Our observations very clearly confirm Paillet's indirect findings of a DWBC along the

TABLE 1. - Launching / releasing date, mission period, mean potential temperature and pressure obtained by the four RAFOS floats and the APEX float.

\begin{tabular}{|c|c|c|c|c|}
\hline & $\begin{array}{l}\text { Launching / } \\
\text { Releasing date }\end{array}$ & $\begin{array}{l}\text { Mission period } \\
\quad \text { (days) }\end{array}$ & $\begin{array}{l}\text { Temperature } \\
\left({ }^{\circ} \mathrm{C}\right)\end{array}$ & $\begin{array}{l}\text { Pressure } \\
\text { (dbar) }\end{array}$ \\
\hline $\begin{array}{l}\text { RAFOS } 490 \\
\text { RAFOS } 491 \\
\text { RAFOS } 492 \\
\text { RAFOS } 493\end{array}$ & $\begin{array}{c}19 / 6 / 1999 \\
19 / 8 / 1999 \\
19 / 10 / 1999 \\
19 / 12 / 1999\end{array}$ & $\begin{array}{l}600 \\
540 \\
600 \\
282\end{array}$ & $\begin{array}{l}3.7 \pm 0.3 \\
3.6 \pm 0.2 \\
3.4 \pm 0.1 \\
3.4 \pm 0.1\end{array}$ & $\begin{array}{c}1518.3 \pm 18.8 \\
1548.3 \pm 41.0 \\
1692.1 \pm 53.8 \\
1754.3 \pm 77.0 \\
\text { Mean }=1627.8\end{array}$ \\
\hline APEX & 19/6/1999 & - & - & $1504.3 \pm 5.0$ \\
\hline
\end{tabular}




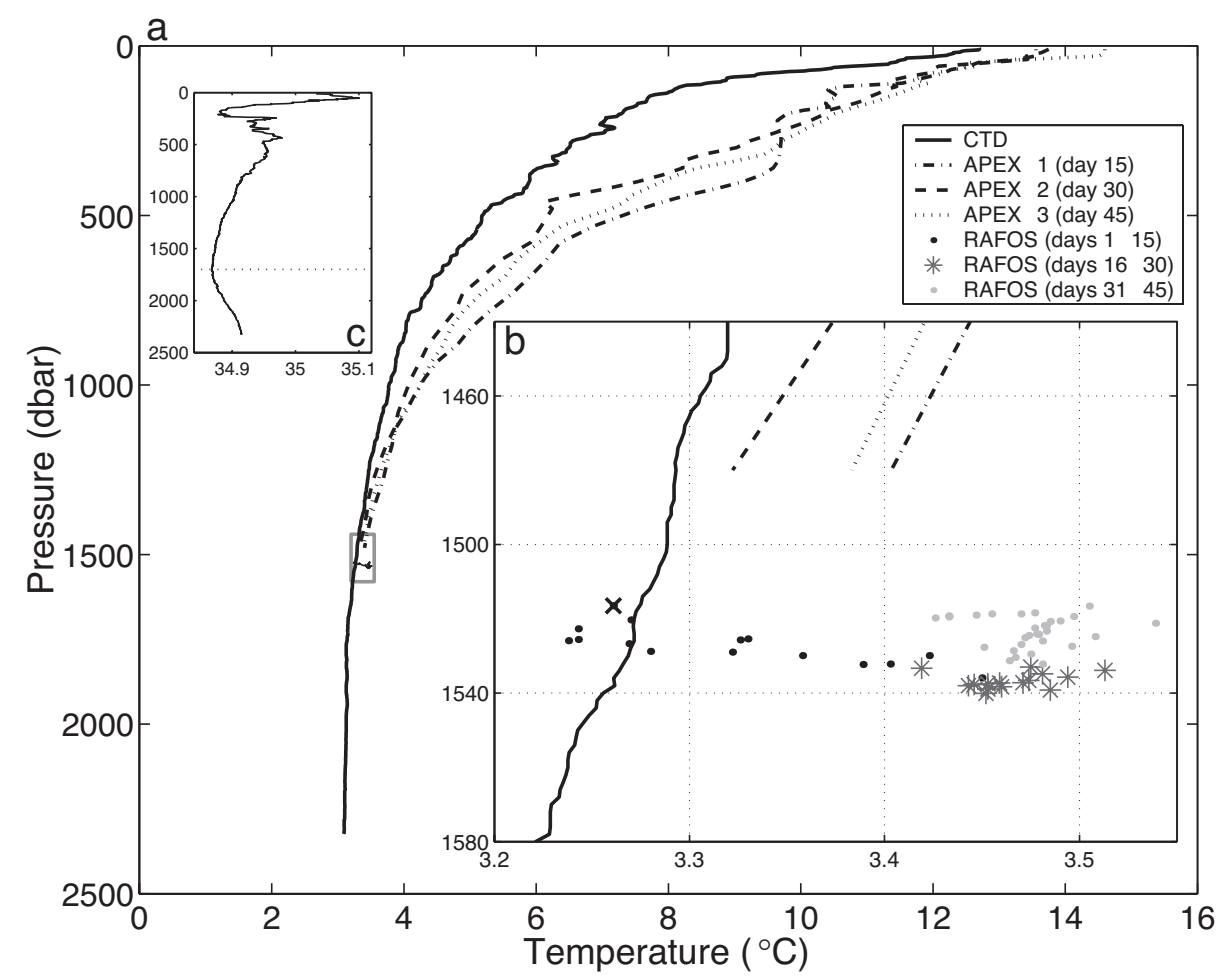

FIG. 2. - a) Comparison between temperatures measured by the CTD probe at the deployment location, the first three APEX profiles and the RAFOS 490 floats during the first 45 days. b) Zoomed representation at the mission depth. The cross labels the first RAFOS temperature after deployment. c) CTD salinity profile at the deployment position, to identify the LSW by the minimum salinity.

eastern side of the MAR (Paillet et al., 1998). More recently Fleischmann et al. (2001) used tracer data to demonstrate the southward spreading of mixtures of ISOW and LSW. This independent geochemical result is compatible with the behaviour of our floats.

Table 1 contains information on mean temperature and pressure values covered by the floats. With a mean drift level of the APEX float of $1504 \pm 5$ dbar, our RAFOS floats drifted on average 124 dbar below the cycling float. The undelayed RAFOS float 490 travelled at $1518 \pm 19$ dbar, i.e. only 14 dbar deeper than its cycling mate APEX 289. The set of floats drifted slightly shallower than the LSW core, located at 1700 dbar as revealed by the CTD cast carried out at the floats' deployment position (Fig. 2c).

The hydrographic conditions within 90 days $(6$ cycles at 15 day intervals) after the initial float deployments are shown in Figure 3 in a Lagrangian frame. During the first two months, i.e. near CGFZ, at mid-depth (1300-1500 $\mathrm{m}$ ) almost no salinity gradients were sensed in the low salinity $(<34.9)$ imprint of LSW. After the fourth profile, the APEX float apparently left the LSW core, as documented by the higher salinity and potential temperature measured at mid-depth. The graph reveals the presence of a well defined deep reaching frontal region in the main thermocline east of CGFZ.

A closer inspection of the thermal evolution measured by our two synoptic Lagrangian devices is shown in Figure 2. We recognize the agreement between the first daily RAFOS temperature and the CTD cast from the deployment operation (Fig. 2b). However, a systematic temperature increase by $0.2^{\circ} \mathrm{C}$ appeared within the first 15 days at $1500 \mathrm{~m}$. This shift was also felt by the APEX after completing its first cycle (APEX-1), when a $0.15^{\circ} \mathrm{C}$ higher temperature was observed after 15 days (dash-dot line). Later temperature profiles show a temperature decrease not observed by the RAFOS float after 30 days (APEX-2), though after 45 days (APEX-3) the temperature approached the range sampled by the RAFOS float. The complete temperature profiles in Figure 2a demonstrate significant deviations in the initial phase of the instruments involved: within the main thermocline large differences of $\mathrm{O}\left(4^{\circ} \mathrm{C}\right)$ within $53 \mathrm{~km}$ (path between launch and first surface location) and delays of only 15-45 days were observed. Apparently we have conducted our floatto-float experiment next to the CGFZ in a well developed frontal region between the northern rim of the subtropical and the southern end of the subpolar gyres. 
$\theta$

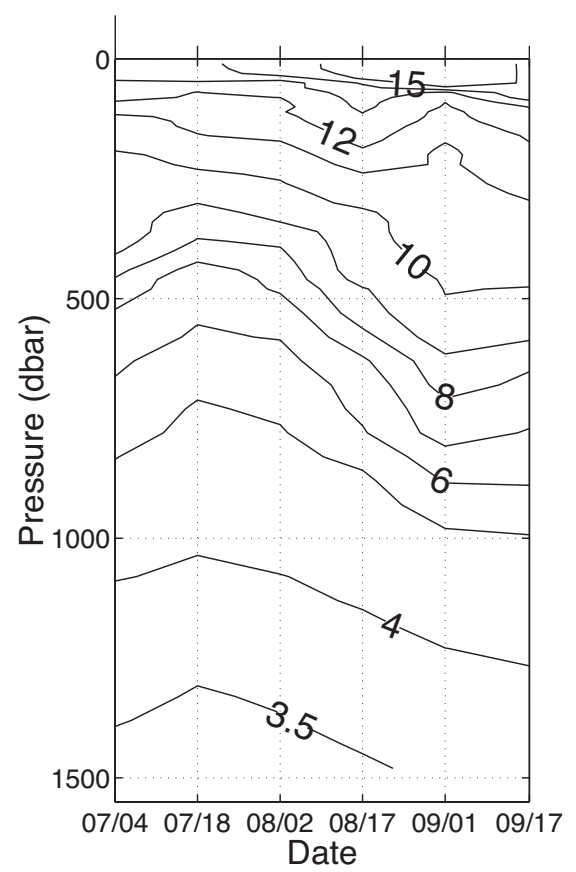

Salinity

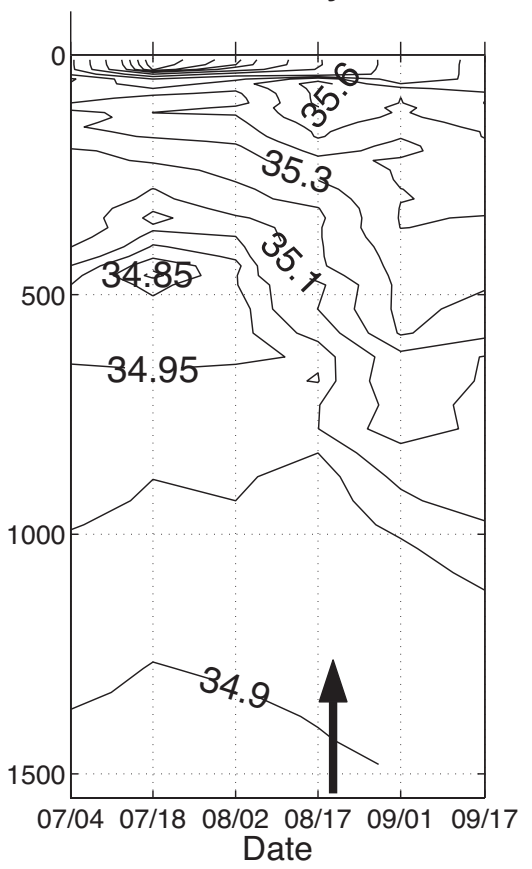

FIG. 3. - Hydrographic variables measured by the profiling APEX float during its initial six cycles, in 1999. The arrow indicates the frontal region encountered by the profiling float after its fourth cycle. Dates in format $\mathrm{mm} / \mathrm{dd}$.

\section{A closer look at the APEX cycle}

The APEX float cycle is shown in Figure 4 in a depth-time frame. A surface drift vector $(S)$ has to be evaluated and subtracted from the raw trajectory to simulate the correct subsurface drift $(s S)$ as seen by the RAFOS floats, since the cycling nature of the APEX float introduces deviations from the expected subsurface trajectory. These deviations can be explained theoretically by the horizontal velocity shear in the water column and by the surface drift induced by the wind stress, as well as some technical aspects described as follows (Fig. 4). Down Time (DT) and Up Time (UT) are parameters set up in the float configuration to optimize the time the float spends at its mission depth (14 days) and also make sure the period at the surface (1 day) is long enough to update its position and send the hydrographic information acquired along vertical displacements via a satellite link. Note that $U T$ consists of the ascending time $\left(a_{t}\right)$ and the surface time $(S)$. The time when the float surfaces $\left(t_{s}\right)$ and the time when it sinks back to its mission depth $\left(t_{h}\right)$ are usually unknown because of limitations in satellite coverage, so only a fraction of $S$ is known $(r)$.

Therefore, steps to estimate a subsurface drift are:

- estimate surfacing $\left(t_{s}\right)$ and descending $\left(t_{h}\right)$ times,
- estimate APEX float location at $t_{s}$ and $t_{h}$,

- evaluate a total surface drift $(S)$, adding the unrecorded track to the recorded one $(r)$ and

- estimate the subsurface drift $(s S)$ by subtracting the surface drift from the total drift.

$t_{s}$ and $t_{h}$ can be calculated using technical information sent by the float itself, according to the procedure supplied by the manufacturer (Dan Webb, personal communication, 2002). Basically, when the float is at the surface it sends all the information several times, sliced into 32-byte messages. Each message contains two numbers, one indicating the message position (slice) and a second number indicating how many times the whole information has been sent. Since we know that each message is send every

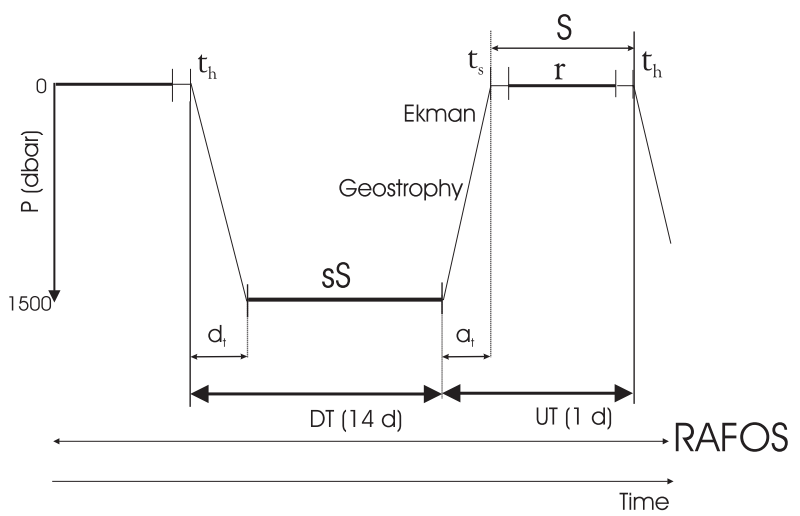

FIG. 4. - APEX float cycle centred on the subsurface (sS) phase. See text for letter definitions. 
90 seconds, $t_{s}$ may be evaluated, with an accuracy of $1 s$ (Ichikawa et al., 2001). $t_{h}$ is estimated statistically, by assuming that the time between $t_{s}$ and the first recorded fixed equals, on average, the time between the last recorded fixed and $t_{h}$.

Once $t_{s}$ and $t_{h}$ are known, a second calculation is performed to estimate their corresponding locations. Several fixes, typically 10 , are recorded during the APEX surface drift. To estimate the APEX location at $t_{s}$ and $t_{h}$, we have to extrapolate the surface drift beyond $r$. A smoothed cubic spline fit option was chosen as the best solution for estimating the total surface drift. This approach agrees with similar considerations by Park et al. (2004), Schmidt et al. (2001) or Davis et al. (1992), all leading to an inaccuracy in surface positioning of $O(3 \mathrm{~km})$.

From the calculations made in the previous sections, the ascending time $\left(a_{t}\right)$ can be estimated using the $U T$ and the time the float stays at the surface. Therefore, the corresponding ascending rate is calculated and the empirical value found is $8.5 \pm 1 \mathrm{~cm}$ $\mathrm{s}^{-1}$. According to the manufacturer, the ascending float rate is supposed to be constant with an estimated value of $8 \mathrm{~cm} \mathrm{~s}^{-1}$, which is in a good agreement with our value. The importance of this result lies in the fact that it supports the procedure used to estimate the time spent by the float at the surface.

In the case of deviations induced by the geostrophic and Ekman shears, no corrections can be performed; therefore, error bounds are given for them instead. Geostrophic velocity shear profiles have been calculated from the floats' CTD data assuming synopticity between two successive temperature and salinity measurements in the water column. An accurate estimate of the geostrophic velocity is senseless because the float is travelling in the same direction as it measures the temperature and salinity. Thus, a lower bound for the rms geostrophic profile typical at the region of study was obtained. On average, the inferred integral displacement amounted to $753 \pm 927 \mathrm{~m}$, which is much less than the errors induced by the inaccuracies in surface drift.

In a similar way we can estimate the float displacements due to Ekman drift and resulting current shear during descents and ascents. Low and moderate wind conditions are typical of the northern rim of the subtropical gyre. For example, the winter mean wind speeds issued by the NOAA (National Oceanic and Atmospheric Administration) Climate Diagnostic Centre for our test region are 12$16 \mathrm{~m} \mathrm{~s}^{-1}$. In view of such moderate mean speeds, the
Ekman depth only covers $<20 \%$ of the sampled water column. At high wind speeds $\left(>70 \mathrm{~m} \mathrm{~s}^{-1}\right)$ a displacement of $\mathrm{O}(1 \mathrm{~km})$ results from the integration of the Ekman spiral. This spatial scale is the same order as the effect of the geostrophic drift in the whole water column covered by the cycling APEX. The mean wind speed range reported by NOAA yields a rather small displacement of only $O(100 \mathrm{~m})$.

\section{Velocity comparison}

Table 2 shows mean speed and direction values measured during 18 months by both types of instruments. The RAFOS daily-speed mean $(\overline{R D})$ is calculated using all daily positions from the four RAFOS floats. RAFOS 14-day-speed mean $(\overline{R 14 D})$ represents the average of the speeds obtained with positions separated by 14 days. APEX subsurface mean speed $(\overline{s S})$ is the subsurface mean speed estimated after performing the correction described in the preceding item.

$\overline{S S}$ can be compared with $\overline{R 14 D}$ to validate our estimate, since $\overline{R 14 D}$ is the mean speed that the APEX float would record in the absence of any perturbation above its mission depth. $\overline{s S}$ underestimates the mean speed by $\mathrm{O}(15 \%)$, though this difference is much smaller than the standard deviation obtained for the speeds. However, $\overline{R D}$ is the most robust estimate we have about the actual current speed, so we may also compare $\overline{s S}$ with $\overline{R D}$. In this case, the APEX float overestimates the current speed by $\mathrm{O}(3 \%)$, though again this number is not statistically significant because of the large variability observed in speeds. A similar analysis may be performed with the directions of the flow measured by the different instruments (Table 2). In this case, each velocity direction estimate indicates a south-eastward subsurface flow, consistent with the direction of the DWBC along the MAR.

Our observations of the velocity field are consistent with previous Langrangian observations in the core layer (1750 m depth) of LSW in the eastern

TABLE 2. - Mean velocity (speed and direction with respect to north) for the RAFOS fleet and the APEX float.

\begin{tabular}{lcc}
\hline & Speed $\left(\mathrm{cm} \mathrm{s}^{-1}\right)$ & Direction $\left({ }^{\circ} \mathrm{N}\right)$ \\
\hline RAFOS Daily Speed $(R D)$ & $3.9 \pm 1.8$ & $105.1 \pm 93.0$ \\
RAFOS 14-days Speed $(R 14 D)$ & $4.7 \pm 1.9$ & $110.1 \pm 90.1$ \\
APEX Subsurface Speed $(s S)$ & $4.0 \pm 2.0$ & $139.1 \pm 90.5$ \\
APEX Surface Speed & $46.4 \pm 60.5$ & $107.8 \pm 97.3$ \\
\hline
\end{tabular}




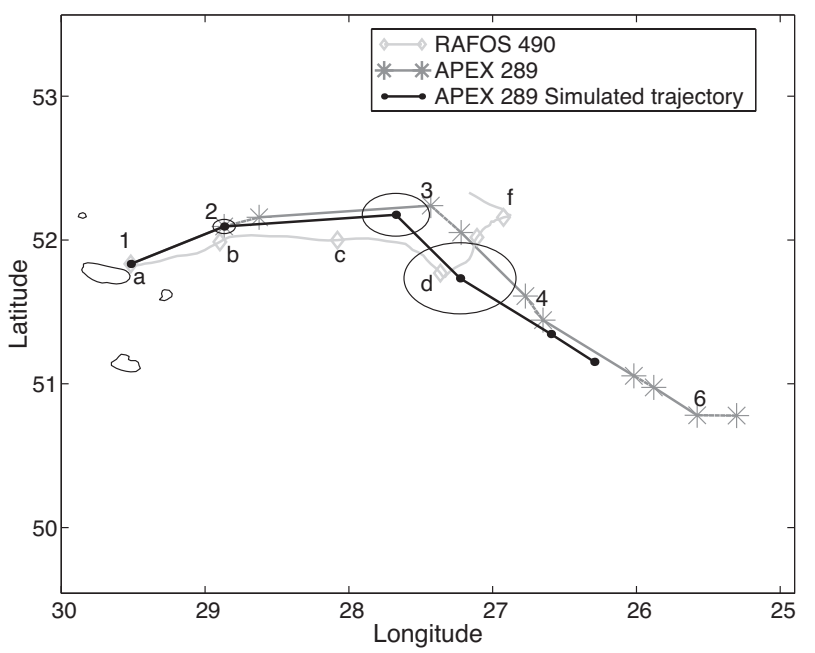

FIG. 5. - Comparison between the initial cycles of the original APEX (stars and numbers) and simulated APEX (dots) with the simultaneous RAFOS float trajectories (diamonds and letters). Ellipses represent the uncertainty by mean surface drift extrapolation, geostrophic shear and Ekman current. Tics denote surface fixes of both instruments. Dashed intervals of the original APEX trajectory represent the periods at the surface. Isobath shown corresponds to $2000 \mathrm{~m}$ depth.

North Atlantic by Speer et al. (2002). Though most of their trajectories cover regions farther east of the Mid-Atlantic Ridge with speeds of about $2 \mathrm{~cm} \mathrm{~s}^{-1}$, they report twice this speed in the more energetic North Atlantic Current, i.e. virtually in the wider vicinity of the Charlie-Gibbs Fracture Zone (50$55^{\circ} \mathrm{N}$ ). Our results shown in Table 2 match their speed estimates.

\section{Initial separation of Floats}

The very first APEX and RAFOS positions, as well as a trajectory simulated after subtracting the surface drift, are displayed in Figure 5. Their mean trajectory characteristics and their separation evolution are also given in Table 3. Ellipses represent the accumulated uncertainty due to inaccuracies in surface position, geostrophic shear and Ekman shear. Until the end of the third cycle both instruments travelled in the same direction, a remark- able feature because the other three RAFOS floats drifted in completely different directions (Fig. 1). This behaviour changed abruptly on day 47 when the RAFOS float drifted to the NE, forced by an eddy or the frontal feature seen in the salinity plot in Figure 3 after 17 August 1999. This discontinuity in the stratification prevents us from studying the two-particle diffusion problem for an extended period.

Although the APEX trajectory simulation shown represents our best estimate, within the first 45 days we still see that the APEX passes the RAFOS float. This deviation might be explained by the intrinsic turbulent diffusivity. Ledwell et al. (1998) found that horizontal turbulent diffusivity depends on the scale considered, reporting $2 \mathrm{~m}^{2} \mathrm{~s}^{-1}$ in the range $1-10 \mathrm{~km}$ and $1000 \mathrm{~m}^{2} \mathrm{~s}^{-1}$ from 30 to $300 \mathrm{~km}$. We can estimate the empirical turbulent diffusivity by means of the separation between the floats after performing corrections (Table 3), according to the expression $\kappa=L^{2} / T$, where $L$ represents the separation between the floats (Table 3 ) and $T$ represents the time elapsed until that cycle, estimated as $T=($ cycle $\times 15)-1$. The scale of our problem, $<100 \mathrm{~km}$, is suitable to be compared with the numbers documented by Ledwell et al. (1998). Our numbers during the first three cycles (121.0, 461.4 and $27.9 \mathrm{~m}^{2} \mathrm{~s}^{-1}$ ) are close to those given by Ledwell et al. (1998), while the diffusivity coefficient after 60 days falls beyond Ledwell's $\kappa$ estimates. In view of this result, during the first three cycles we can relate the deviation observed between the floats to the turbulent diffusivity, though our numbers cannot be considered as estimates of the actual diffusivity coefficient.

\section{CONCLUSIONS}

According to their large scale trajectories, both types of floats prove the presence of a Deep Western

TABLE 3. - Mean speeds for the APEX and RAFOS 490 floats and distances between them $(L)$, during the first two months of their mission. Turbulent diffusion coefficients $(\kappa)$ after every cycle are also shown.

\begin{tabular}{|c|c|c|c|c|}
\hline & 1 & 2 & 3 & 4 \\
\hline APEX Subsurface Speed $\left(\mathrm{cm} \mathrm{s}^{-1}\right)$ & 4.1 & 6.3 & 4.5 & 4.8 \\
\hline RAFOS Speed $\left(\mathrm{cm} \mathrm{s}^{-1}\right)$ & 3.5 & 4.3 & 4.3 & 2.5 \\
\hline APEX Dir $\left({ }^{\circ} \mathrm{N}\right)$ & 57.0 & 83.7 & 148.0 & 134.4 \\
\hline RAFOS Dir $\left({ }^{\circ} \mathrm{N}\right)$ & 68.2 & 88.6 & 117.4 & 32.3 \\
\hline $\mathrm{L}(\mathrm{km})$ & 12.1 & 34.0 & 10.3 & 82.8 \\
\hline $\mathrm{k}\left(\mathrm{m}^{2} \mathrm{~s}^{-1}\right)$ & 121.0 & 461.4 & 27.9 & 1344.9 \\
\hline
\end{tabular}


Boundary Current (DWBC) at the eastern side of the Mid-Atlantic Ridge. The RAFOS floats resolve the eddy field associated to this DWBC while the APEX float meanders during its mission.

The main source of error when estimating the subsurface velocity originates from not being able to record the complete float path at the surface, while the Ekman shear is a lower source of error in the vicinity of the Charlie-Gibbs Fracture Zone. However, the error induced by the geostrophic shear amounts to at least $753 \pm 927 \mathrm{~m}$, and the comparison of velocities estimated from both types of floats suggests that this should not be a significant source of error.

The APEX float offers velocity estimates that are statistically similar to those given by the RAFOS floats, both in their speed and direction of the measured flow. These speed estimates are consistent with independent RAFOS float values and with other speed estimates in the region (Speer et al., 1999).

Turbulent diffusivity may be the mechanism responsible for the observed initial float separation we still observe after performing corrections. The hydrographic conditions reveal the presence of mesoscale structures that induce our mini-cluster breakdown, preventing us from studying their separation for an extended period. During further cycles, increasing distance is caused by varying drifts induced by stratification changes and current and Ekman shears, farther up in the water column.

Finally, these oceanic observations support exploiting the Lagrangian nature of profiling floats.

\section{ACKNOWLEDGEMENTS}

The first author would like to thank the Dirección General de Universidades e Investigación del Gobierno de Canarias for supporting his stay at the Leibnitz-Institut für Meereswissenschaften (former Institut für Meereskunde) an der Universität Kiel, where this study was carried out. Many thanks are also due to the Gyroscope project of the European Commission (Grant EVK2-CT-2000-00087) for being the context of this work and to Klaus Peter Koltermann for generously supplying the APEX float data. The reference float observations were funded by the Deutsche Forschungsgemeinschaft (SFB490), Bonn. We appreciate the processing work of RAFOS floats made by Matthias Lankhorst and his comments on the RAFOS system. We would also like to thank two anonymous reviewers who kindly suggested ideas that improved the final result of this manuscript.

\section{REFERENCES}

Böhme, L. and U. Send. - 2005. Objective analyses of hydrographic data for referencing profiling float salinities in highly variable environments. Deep-Sea Res. II, 52(3-4): 651-664.

Bower, A., B. L. Cann, T. Rossby, W. Zenk, W.J. Gould, K. Speer, P. Richardson, M. Prater and H.-M. Zhang. - 2002. Directly measured mid-depth circulation in the northeast North Atlantic Ocean. Nature, 419: 603-607.

Davis, R., J. Sherman and J. Dufour. - 2001. Profiling ALACEs and other advances in autonomous subsurface floats. J. Atmos. Oceanic Technol., 18: 982-993.

Davis, R., D. Webb, L. Regier and J. Dufour. - 1992. The autonomous lagrangian circulation explorer (ALACE). $J$. Atmos. Oceanic Technol., 9: 264-285.

Davis, R. and W. Zenk. - 2001. Subsurface lagrangian observations during the 1990s. In: J. Gould, G. Siedler and J. Church (eds.) Ocean Circulation and Climate (Observing and Modeling the Global Ocean), pp. 123-139. Academic Press, San Diego.

Faure, V. and K. Speer. - 2005. Labrador Sea Water circulation in the Northern North Atlantic Ocean . Deep-Sea Res. II, 52(3-4): $565-581$.

Fleischmann, U., H. Hildebrandt, A. Putzka and R. Bayer. - 2001. Transport of newly ventilated deep water from Iceland Basin to the Westeuropean Basin. Deep-Sea Res. I, 48: 1793-1819.

Gould, W.J. - 2005. From Swallow floats to Argo-the development of neutrally buoyant floats. Deep-Sea Res. II, 52(3-4): 529-543.

Ichikawa, Y., Y. Takatsuki, K. Mizuno, N. Shikama and K. Takeuchi. - 2001. Estimation of drifting velocity and error at parking depth for Argo float. Report of Japan Marine Science and Technology Center, 44: 81-90.

Krauss, W. - 1986. The North Atlantic Current. J. Geophys. Res., 91: 5061-5074.

Ledwell, J., A. Watson and C. Law. - 1998. Mixing of a tracer in the pycnocline. J. Geophys. Res., 103(C10): 21499-21529.

Loaec, G., N. Cortes, M. Menzel and J. Moliera. - 2002. Provor: A hydrographic profiler based on marvor technology. http://www.ifremer.fr/dtmsi/produits/marvor/o98-484.pdf

Paillet, J., M. Arhan and M. McCartney. - 1998. Spreading of Labrador Sea Water in the eastern North Atlantic. J. Geophys. Res., 103(C7): 10223-10239.

Park, J., K. Kim and W. Crawford. - 2004. Inertial currents estimated from surface trajectories of Argo floats. Geophys. Res. Lett., 31(13), 10.1029/2004GL020191.

Rossby, T., D. Dorson and J. Fontaine. - 1986. The RAFOS system. J. Atmos. Oceanic Technol., 3(4): 672-679.

Schmidt, C., R. Molinari and S. Garzoli. - 2001. New observations of the intermediate depth circulation in the Tropical Atlantic. $J$. Mar. Res., 59: 281-312.

Schott, F., J. Meincke, G. Meinecke, S. Neuer and W. Zenk. -2000. North Atlantic 1999, Cruise No. 45, 18 May - 4 November 1999. Meteor-Berichte 00-4, Universität Hamburg.

Smith, N., R. Bailey, O. Alves, T. Delcroix, K. Hanawa, E. Harrison, B. Keeley, G. Meyers, B. Molinari and D. Roemmich. - 2001. The upper ocean thermal network. In: C.J. Koblinsky and N.R. Smith (eds.), Observing the Ocean in the 21st Century, pp. 259-284. Melbourne.

Speer, K., W.J. Gould and J. LaCasce. - 1999. Year-long float trajectories in the Labrador Sea Water of the eastern North Atlantic Ocean. Deep-Sea Res. II, 46: 165-179.

Wong, A., G.C. Johnson and W.B. Owens. - 2003. Delayedmode calibration of autonomous CTD profiling float salinity data by theta-S climatology. J. Atmos. Oceanic Technol., 20(2): 308-318.

Zenk, W., A. Pinck, S. Becker and P. Tiller. -2000 . The float park: a new tool for a cost-effective collection of lagrangian time series with dual release RAFOS floats. J. Atmos. Oceanic Technol., 17(10): 1439-1443.

Scient. ed.: J. Font 